\title{
Preparation of carbon nanotubes using cvd CVD method
}

\author{
Iwona Pełech \\ West Pomeranian University of Technology, Szczecin, Institute of Chemical and Environment Engineering, ul. Pułaskiego 10, \\ 70-322 Szczecin, Poland, e-mail: ipelech@zut.edu.pl
}

In this work preparation and characteristic of modified nanocarbons is described. These materials were obtained using nanocrystalline iron as a catalyst and ethylene as a carbon source at $700^{\circ} \mathrm{C}$. The influence of argon or hydrogen addition to reaction mixture was investigated. After ethylene decomposition samples were hydrogenated at $500^{\circ} \mathrm{C}$. As a results iron carbide $\left(\mathrm{Fe}_{3} \mathrm{C}\right)$ in the carbon matrix in the form of multi walled carbon nanotubes was obtained. After a treatment under hydrogen atmosphere iron carbide decomposed to iron and carbon and small iron particles agglomerated into larger ones.

Keywords: iron catalyst, carbon nanomaterials, ethylene decomposition, hydrogenation.

\section{INTRODUCTION}

Nanocarbons, including CNTs (carbon nanotubes), can be synthesized using several techniques: laser ablation, arc discharge and chemical vapor deposition (CVD). The last of these methods consists in decomposition of carbon-containing compounds (e.g. methane, ethane, ethylene) on transition metal catalysts (iron, cobalt, nickel) ${ }^{\mathbf{1}-\mathbf{3}}$. In many cases, to improve metal particles dispersion, catalyst on supports are applied. The most popular are aluminum and silicon oxides ${ }^{4}$. CVD method is characterized by simple experimental system, easy available reagents, a large yield of material, low production costs and is very attractive for large scale production. The main disadvantage of the method is the formation of a significant amount of other products, such as amorphous carbon or graphitic particles. Additionally after synthesis, metal particles should be separated from carbon material.

Amorphous carbon can be eliminated by chemical oxidation which includes gas phase oxidation using air or steam $^{\mathbf{5}-6}$ or by liquid phase oxidation using potassium permanganate, hydrogen peroxide or perchloric acid ${ }^{7-8}$. A little data are available with respect to the gasification of carbon by hydrogen ${ }^{\mathbf{- 1 0}}$.

Carbon nanomaterials could be applied as components in polymer composites or catalyst supports ${ }^{\mathbf{1 1}} \mathbf{- 1 2}$. They can be also used as solid sorbents in the processes of $\mathrm{SO}_{2}$ removing from waste gases. Recently, active carbon and activated carbon fibres are used for this purpose ${ }^{\mathbf{1 3}-\mathbf{1 4}}$.

This manuscript presents preparation of carbon nanotubes using ethylene as a carbon source and iron catalyst without support. This material will be applied to remove $\mathrm{SO}_{2}$ from waste gases using absorption and adsorption of $\mathrm{SO}_{2}$ connected with its oxidation to $\mathrm{SO}_{3}$ and sulfuric acid formation. In the first stage of these studies iron in carbon matrix will be investigated. In the next stage iron particles will be removed and another metal will be investigated. Therefore, in the manuscript we present results of hydrogenation process as well, which seems to improve a removal of iron particles from carbon matrix.

\section{EXPERIMENTAL}

Nanocarbon materials were obtained as a result of ethylene decomposition on iron catalyst. This catalyst was prepared by a fusion of magnetite $\left(\mathrm{Fe}_{3} \mathrm{O}_{4}\right)$ with a small amount of promoter oxides $\left(\mathrm{Al}_{2} \mathrm{O}_{3}, \mathrm{CaO}\right)$ in an electric furnace. The role of promoter oxides was to stabilize the nanocrystalline iron structure at elevated temperatures. The obtained alloy was crushed and sieved in order to obtain a fraction of $1.2-1.5 \mathrm{~mm}$ and next reduced under hydrogen. As a result of reduction nanocrystalline iron was obtained and the promoters remained in the oxide state. In order to avoid rapid oxidation of metallic iron, the samples were passivated under nitrogen containing traces of oxygen. The chemical composition of the reduced and next passivated samples was determined using ICP - AES (Inductively Coupled Plasma Atomic Emission Spectroscopy) method (Yvon - Jobin). The samples contained iron and $2.9 \%$ of $\mathrm{Al}_{2} \mathrm{O}_{3}, 3.0 \%$ of $\mathrm{CaO}$ and 0.7 of $\mathrm{K}_{2} \mathrm{O}$. The mean crystallite size of iron determined using an X-ray diffraction method (Philips X'Pert) and calculated using the Scherrer's equation was equal to $17 \mathrm{~nm}$.

The carburisation processes were carried out in a high temperature furnace (HST 12/400 Carbolite). The samples of catalyst were placed in a quartz boats inside a quartz tube. Before ethylene decomposition, all samples were reduced polythermally at the temperature raising from $20^{\circ} \mathrm{C}$ to $500^{\circ} \mathrm{C}$ and next isothermally at $500^{\circ} \mathrm{C}$ for 60 minutes. The reduction process was carried out in order to remove a thin passivation layer.

In the second stage, hydrogen was replaced by ethylene or a mixture of ethylene and hydrogen or a mixture of ethylene and argon. The syntheses were performed under atmospheric pressure at $700^{\circ} \mathrm{C}$ for 60 minutes. After carburisation the samples were cooled to the room temperature under argon flow or were hydrogenated at $500^{\circ} \mathrm{C}$.

The samples after ethylene decomposition or hydrogenation were characterized using HRTEM (High Resolution Transmission Electron Microscopy) method (Jeol JEM 3010). This method was used to investigate the morphology of the samples. The phase composition of material and graphitization degree (counting time 10s, step 0.02) was studied using X-ray diffraction method (Philips X'Pert).

\section{DISCUSSION AND RESULTS}

Nanocarbons were prepared by ethylene decomposition on iron catalyst at $700^{\circ} \mathrm{C}$. In Fig. 1 the dependence of a relative increase of carbon mass on ethylene flow is presented. During the first experiment ethylene flow equaled 


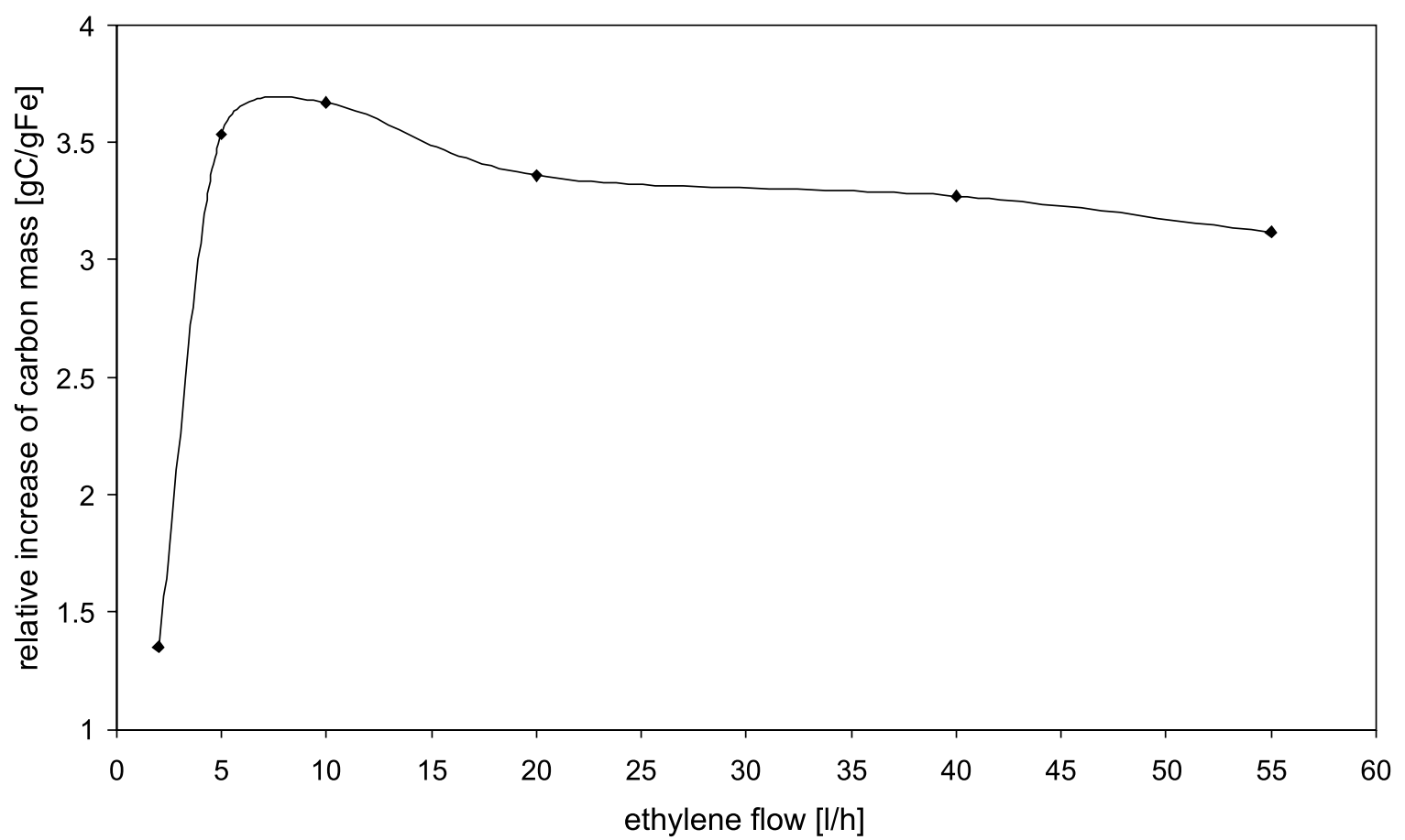

Figure 1. The dependence of relative increase of carbon mass as a function of ethylene flow at $700^{\circ} \mathrm{C}$

$2 \mathrm{l} / \mathrm{h}$ and carbon yield was very low (about $1.3 \mathrm{gC} / \mathrm{gFe}$ ). When the ethylene flow increased to $5 \mathrm{l} / \mathrm{h}$ and next to 10 $1 / \mathrm{h}$, carbon yield increased rapidly and amounted about $3.5 \mathrm{gC} / \mathrm{gFe}$. Further increasing of ethylene flow caused a slight decrease of carbon yield up to $3 \mathrm{gC} / \mathrm{gFe}$. Similar results were presented by Khavrus et al. ${ }^{\mathbf{1 5}}$ who synthesized carbon nanotubes using Ni catalyst and ethylene. Yield of MWNTs had a tendency to increase with decreasing ethylene concentrations. Authors explained this fact by a fast carbonization of active metal sites at the catalyst surface for higher ethylene concentration at the beginning of the synthesis. Donato et al. ${ }^{\mathbf{1 6}}$ observed another tendency during synthesis of CNTs by iron-catalyzed CVD in $\mathrm{C}_{2} \mathrm{H}_{6} / \mathrm{H}_{2}$ atmosphere. They claimed that increasing $\mathrm{C}_{2} \mathrm{H}_{6}$ flow-rate allows achieving higher carbon yields. However, the si- multaneous increase of $\mathrm{C}_{2} \mathrm{H}_{6}$ flow-rate leads to progressive loss of selectivity and structural order.

In order to determine the influence of adding either hydrogen or argon to ethylene, at first a hydrocarbon decomposition was conducted, and next argon or hydrogen were added to ethylene to obtain a $\mathrm{C}_{2} \mathrm{H}_{4}$ : $\mathrm{Ar}\left(\mathrm{H}_{2}\right)$ ratio of $3: 1,1: 1,1: 3,1: 8$ and 1:16. The total flow amounted to 401/h. In the Fig. 2 the dependence of relative increase of carbon mass on ethylene partial pressure is presented. When ethylene was diluted with argon, carbon yield slightly decreased. In the range from 0.75 to 0.25 ethylene partial pressure had no more influence on the carbon quantity and carbon yield amounted about $3 \mathrm{gC} / \mathrm{gFe}$. After this point carbon yield strongly decreased and amounted only 0.8 $\mathrm{gC} / \mathrm{gFe}$ when ethylene partial pressure equaled to 0.05 at.

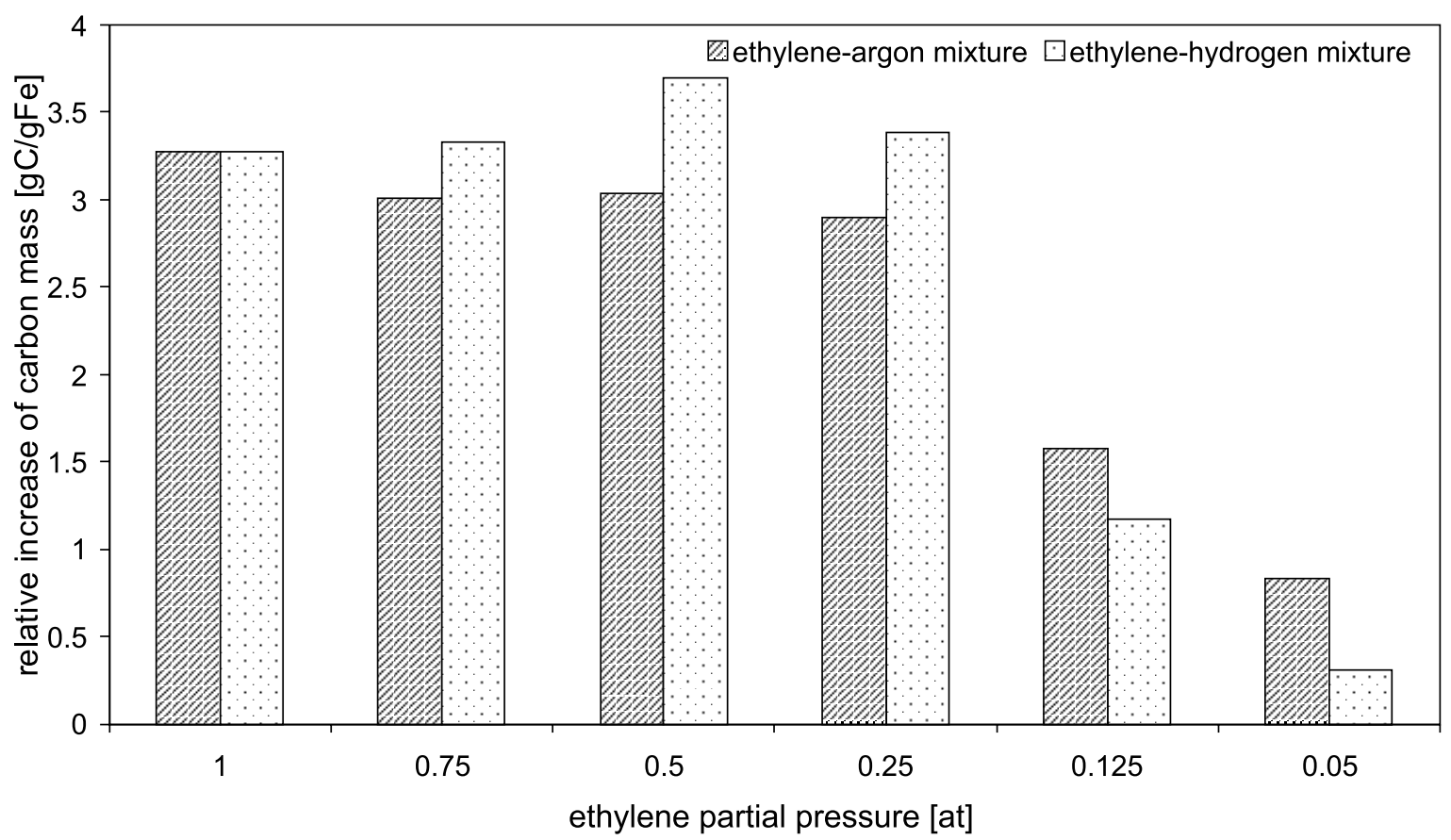

Figure 2. The dependence of relative increase of carbon mass as a function of ethylene partial pressure in the ethylene - argon and ethylene - hydrogen mixture 
Nagaraju et al. ${ }^{17}$ studied decomposition of acetylene on iron, cobalt and mixture of iron and cobalt on $\mathrm{Al}_{2} \mathrm{O}_{3}$ and $\mathrm{SiO}_{2}$. At $700^{\circ} \mathrm{C}$, the carbon deposit increased with increase in the rate of flow of acetylene.

In the case of ethylene - hydrogen mixture, the carbon yield increased in the range of ethylene partial pressure from 0.75 to 0.25 and oscillated between 3.3 and $3.7 \mathrm{gC} /$ gFe. Similarly like in the case of $\mathrm{C}_{2} \mathrm{H}_{4}$-Ar mixture in the range of $\mathrm{C}_{2} \mathrm{H}_{4}$ partial pressure from 0.125 to 0.05 , a decrease of carbon yield was observed and finally amounted about $0.3 \mathrm{gC} / \mathrm{gFe}$. Similar results were obtained by Escobar et al. ${ }^{18}$. They studied the effect of acetylene partial pressure on the yield and morphological properties of MWNTs synthesized on $\mathrm{Fe} / \mathrm{SiO}_{2}$ catalyst. At low acetylene concentration lower values of carbon yield were obtained. Simultaneously, CNTs synthesized with low $\mathrm{C}_{2} \mathrm{H}_{2}$ concentration were more regular and with lower amount of amorphous carbon than those synthesized with high concentration. Tripol'skii et al. ${ }^{19}$ showed the dependence of the specific yield on ethylene concentration. The curve had a low angle form with a weakly expressed maximum at ethylene concentration of $7 \%$. The other results were obtained by Venegoni et al. ${ }^{20}$. They studied the influence of the $\mathrm{H}_{2}: \mathrm{C}_{2} \mathrm{H}_{4}$ ratio on the deposited yield produced from $\mathrm{H}_{2}$ $\mathrm{C}_{2} \mathrm{H}_{4}$ mixtures on $\mathrm{Fe} / \mathrm{SiO}_{2}$ catalyst in fluidized bed. Even in the absence of hydrogen, significant decomposition was noticed. Increasing the $\mathrm{H}_{2}: \mathrm{C}_{2} \mathrm{H}_{4}$ ratio until a value of 2 resultated in a considerable improvement of the deposition yield. Further increase of this ration led to a moderate increase of the deposited yield.

The phase composition of iron catalyst after ethylene decomposition was studied using XRD method. A diffraction pattern is showed in Fig. 3A. Peaks corresponding to graphite and cementite phase were observed. In the sample some peaks attributed to $\alpha$-Fe phase were also observed. It indicates that under experimental conditions the conversion of iron into cementite was not complete.
XRD method was also useful to determine a graphitization degree. For that purpose the diffraction patterns in the narrow angle range from 20 to $302 \Theta$ were acquired, to measure precisely the peak of graphite (002) phase. These studies were carried out for the samples synthesized using ethylene - argon and ethylene - hydrogen mixture in various ratios. Graphitization degrees for all samples were calculated on the basis of the equation of Marie and Mering ${ }^{21}$ :

$d=3.354+0.086(1-g)$

where: $d$ - interplanar distance [ $\AA$ ], g - graphitization degree [\%], whereas interplanar distances were calculated using following equation:

$d_{h k l}=\frac{\lambda}{2 \sin \theta}$

where: $d_{\text {hkl }}$ - interplanar distance, $\lambda-X$-ray wavelength, $\Theta$ - diffraction angle.

The values of interplanar distances and graphitization degrees are presented in Table 1.

In the ideal graphite crystalline structure, the value of interplanar distance equals to $0.335 \mathrm{~nm}$ and then graphitization degree equals to $100 \%$. The limiting value of interplanar distance is $0.344 \mathrm{~nm}$. Above this value, it is assumed that carbon material has a disordered structure $^{21}$. In the samples under the study, the values of interplanar distances equal about $0.340 \mathrm{~nm}$ and were greater than in the ideal graphite structure but lower than for a disordered structure. This phenomena was caused by presence of defects in graphite structure. It was found that graphitization degree did not change for particular samples, therefore it was independent from ethylene contribution in the ethylene - argon and also in the ethylene hydrogen mixture.

After ethylene decomposition, some of the samples were treated under hydrogen atmosphere at $500^{\circ} \mathrm{C}$. Diffraction pattern of this material is presented in Fig. 3B. Under experimental conditions cementite was decomposed to

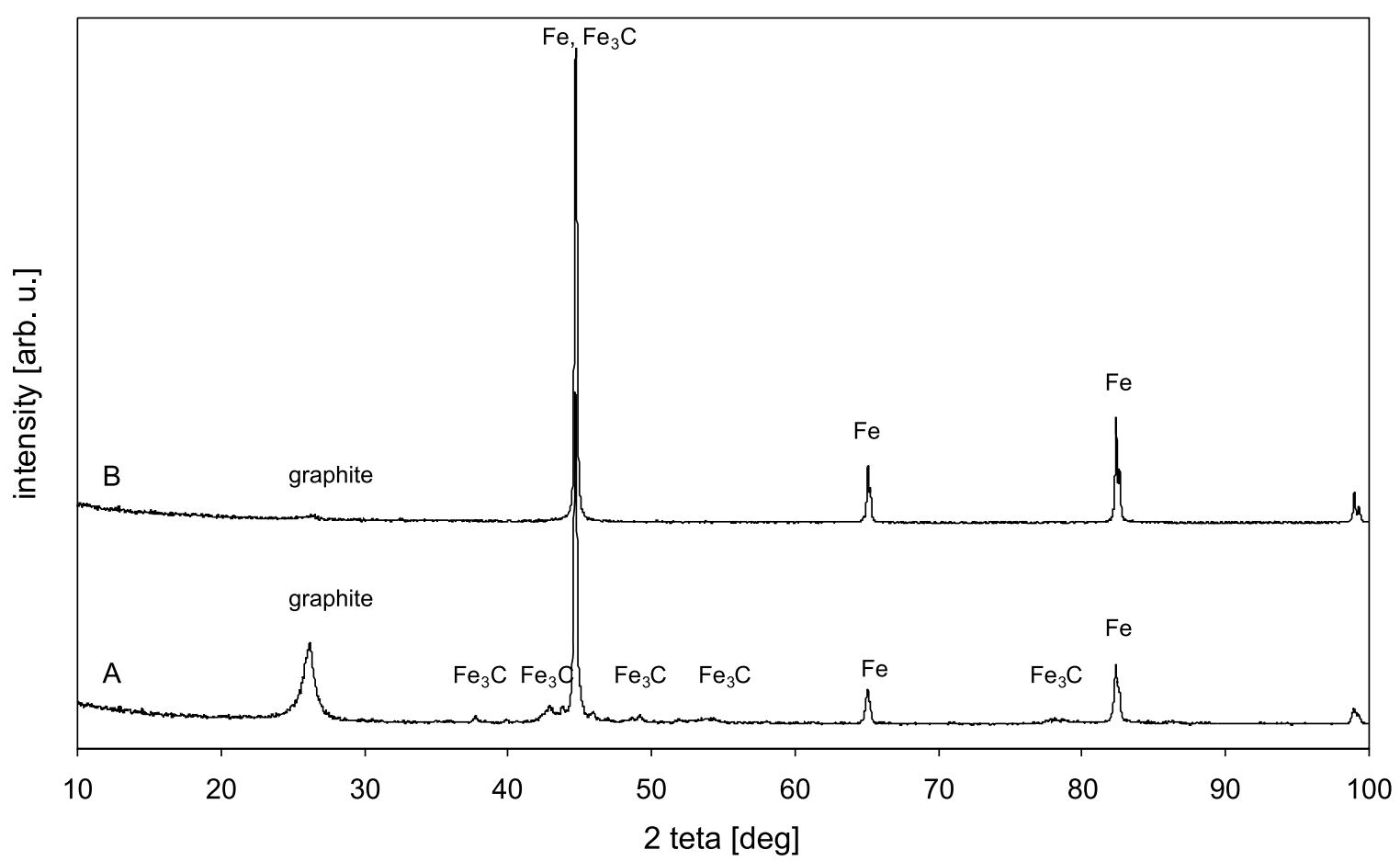

Figure 3. Diffraction patterns of iron catalyst after ethylene decomposition (A) and carbon material after hydrogenation at $550^{\circ} \mathrm{C}(\mathrm{B})$ 
Table 1. Values of interplanar distances and graphitization degrees for the samples synthesized using ethylene - argon and ethylene - hydrogen mixture at $700^{\circ} \mathrm{C}$

\begin{tabular}{|l|c|c|c|c|}
\hline Reaction mixture & Ethylene partial pressure [at] & $\mathrm{C}_{002}$ position $2 \Theta[\mathrm{deg}]$ & Interplanar distance $\mathrm{d}_{002}[\AA]$ & Graphitization degree [\%] \\
\hline \multirow{5}{*}{ Ethylene-argon } & 1 & 26.23 & 3.4071 & 38.17 \\
\cline { 2 - 5 } & 0.75 & 26.23 & 3.4071 & 38.22 \\
\cline { 2 - 5 } & 0.5 & 26.15 & 3.4077 & 37.58 \\
\cline { 2 - 5 } & 0.25 & 26.21 & 3.4073 & 38.07 \\
\cline { 2 - 5 } & 0.125 & 26.09 & 3.4073 & 38.01 \\
\hline \multirow{5}{*}{\begin{tabular}{l} 
Ethylene- \\
\cline { 2 - 5 }
\end{tabular}} & 0.05 & 26.19 & 3.4068 & 38.63 \\
\cline { 2 - 5 } & 1 & 26.23 & 3.4072 & 39.17 \\
\cline { 2 - 5 } & 0.75 & 26.27 & 3.4058 & 40.81 \\
\cline { 2 - 5 } & 0.5 & 26.27 & 3.4049 & 37.44 \\
\cline { 2 - 5 } & 0.25 & 26.19 & 3.4078 & 36.36 \\
\hline
\end{tabular}
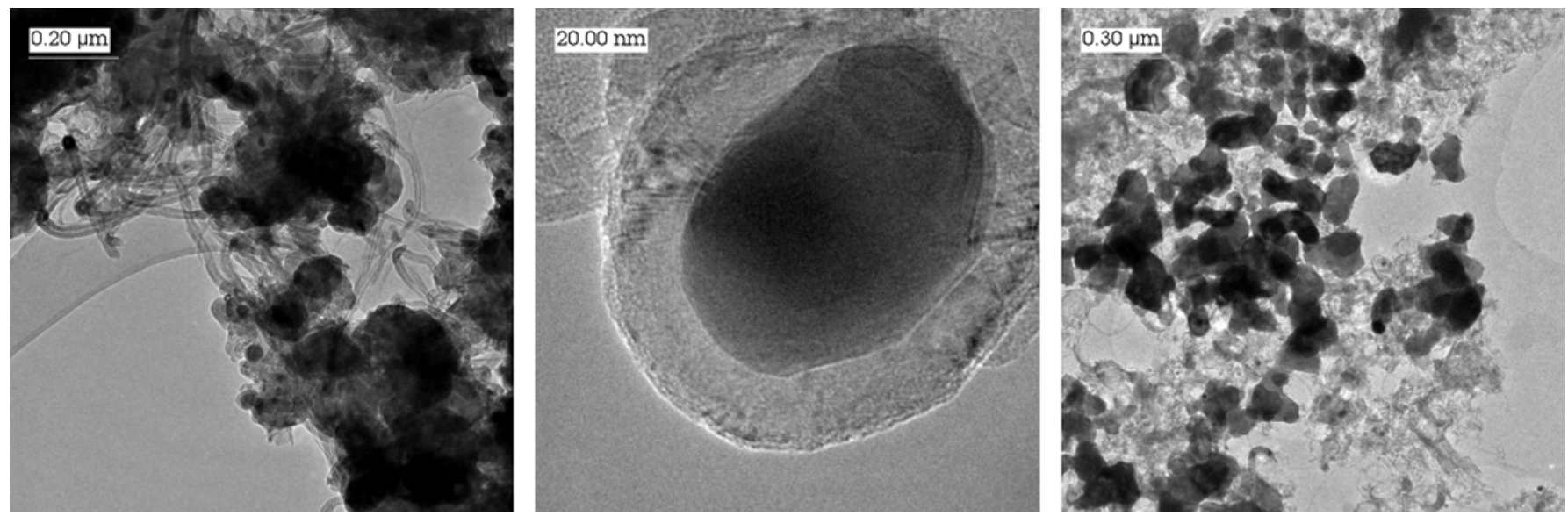

Figure 4. TEM images of the samples: after $\mathrm{C}_{2} \mathrm{H}_{4}$ decomposition at $700^{\circ} \mathrm{C}(\mathrm{A}, \mathrm{B})$ and hydrogenation at $500^{\circ} \mathrm{C}(\mathrm{C})$

iron and carbon. In connection with this phenomenon on the diffraction pattern peaks derived from iron carbide were not observed and only peaks corresponding to iron were visible. Additionally a small intensity graphite peak was visible.

Morphology of obtained materials was characterized using transmission electron microscopy. It was made a comparison between the sample after synthesis using ethylene - argon mixture $(1: 1)$ at $700^{\circ} \mathrm{C}$ and the same sample after a following hydrogenation at $500^{\circ} \mathrm{C}$. TEM images are presented in Fig. 4. It was found that obtained carbon was mainly in the form of multi walled carbon nanotubes (Fig. 4A). Their external diameters were in the range from 10 to $40 \mathrm{~nm}$. On the outer surface of MWNTs, amorphous carbon was observed. Larger catalyst particles - diameter from 50 to $200 \mathrm{~nm}$ - were surrounded by some graphitic layers (Fig. 4B). This indicates that only small catalyst particles were suitable for the growth of carbon nanotubes. After hydrogenation multi walled carbon nanotubes were still present. Nevertheless iron particles agglomerated into larger ones and separated from fibrous structures (Fig. 4C).

\section{CONCLUSIONS}

The synthesis of modified nanocarbons was performed through ethylene decomposition on nanocrystalline iron catalyst with addition of small amount of promoter oxides $\left(\mathrm{Al}_{2} \mathrm{O}_{3}, \mathrm{CaO}\right)$. It was found that ethylene partial pressure in the ethylene - argon or ethylene - hydrogen mixture affected the carbon yield but did not have the influence on the graphitization degree of obtained material. As a result of hydrogenation process small metal particles agglomerated into larger and carbon remained in the form of multi walled carbon nanotubes, what can be useful to remove of the catalysts from the obtained product.

\section{Acknowledgements}

Author is grateful to Dr. M. J. Woźniak (Faculty of Materials Science and Engineering, Warsaw University of Technology) for the measurements using High Resolution Transmission Electron Microscopy.

This research was carried out under the funding of Polish Ministry of Science and Higher Education (NN 205112 135).

\section{LITERATURE CITED}

1. Balogh, Z., Halasi, G., Korbély, \& Hernadi, K. (2008). CVD-syntesis of multiwall carbon nanotubes over potassium-doped supported catalysts. Appl. Catal. A: General 344, 191 - 197. doi:10.1016/j.apcata.2008.04.019.

2. Singh, B.K., Ryu, H., Rajeev, C.C., Nguyen, D.H., Park, S.J., Kim, S. \& Lee, J.R. (2006). Growth of multiwalled carbon nanotubes from acetylene over in situ formed Co nanoparticles on $\mathrm{MgO}$ support. Solid State Commun. 139, 102 - 107. doi:10.1016/j.ssc.2006.05.021 .

3. Reddy, N.K., Meunier, J-L. \& Coulombe, S. (2006). Growth of carbon nanotubes directly on a nickel surface by thermal CVD. Mater. Sci. 60, 3761 - 3765. doi:10.1016/ j.matlet.2006.03.109. 
4. Park, C. \& Keane, M.A. (2004). Catalyst support effect in the growth of structured carbon from the decomposition of ethylene over nickel. J. Catal. 221, 386 - 399. doi:10.1016/ j.jcat.2003.08.014.

5. Chen, Ch.M., Dai, Y.M., Huang, J.G. \& Jehng, J.M. (2006). Intermetallic catalyst for carbon nanotubes (CNTs) growth by thermal chemical vapor deposition method. Carbon 44, 1808 - 1820. doi:10.1016/j.carbon.2005.12.043.

6. Tobias, G., Shao, L.D., Salzmann, C.G., Huh, Y. \& Green, M.L.H. (2006). Purification and opening of carbon nanotubes using steam. J. Phys. Chem. B 110, 22318 - 22322. doi: 10.1021/jp0631883.

7. Wang, Y.H., Shan, H.W., Hauge, R.H., Pasquali, M. \& Smalley, R.A. (2007). A highly selective, one-pot purification method for single-walled carbon nanotubes. J. Phys. Chem. B 111, 1249 - 1252. doi: 10.1021/jp068229+.

8. Hernadi, K., Siska, A., Thien-Nga, L., Forro, L. \& Kiricsi, I. (2001). Reactivity of different kinds of carbon during oxidative purification of catalytically prepared carbon nanotubes. Solid State Ionics 141\&142, 203- 209. doi:10.1016/ S0167-2738(01)00789-5.

9. Pełech, I. \& Narkiewicz, U. (2009). Studies of hydrogen interaction with carbon deposit containing carbon nanotubes. J. Non-Cryst. Solids 355, 1370 - 1375. doi: 10.1016/ j.jnoncrysol.2009.05.025.

10. Fonseca, A., Hernadi, K., Piedigrosso, P., Colomer, J.F., Mukhopadhyay, K., Doome, R., Lazarescu, S., Brio, L.P., Lambin, Ph., Thiry, P.A., Bernaerts, D. \& Nagy, J.B. (1998). Synthesis of single- and multi-wall nanotubes over supported. Appl. Phys. A 67, 11 - 22. doi: 10.1007/ s003390050732.

11. Narkiewicz, U., Pełech, I., Rosłaniec, Z., Kwiatkowska, M. \& Arabczyk, W. (2007). Preparation of nanocrystalline iron-carbon materiale as fillers for polymers. Nanotechnology 18, 405601. doi:10.1088/0957-4484/18/40/405601.

12. Rocco, A.M., Cristiane, C.A., Macedo, M.I.F., Maestro, L.F. \& Herbst, M.H. (2008). Purification of cataltically produced carbon nanotubes for use as support for fuel cell cathode Pt catalyst. J. Mater. Sci. 43, 557 - 567. doi: 10.1007/ s10853-007-1779-3.

13. Raymundo-Pinero, E., Cazorla-Amorós, D., SalinaMartinez de Lecea, C. \& Linares-Solano, A. (2000). Factors controling the $\mathrm{SO}_{2}$ removal by porous carbons: relevance of the $\mathrm{SO}_{2}$ oxidation step. Carbon 38, 335 - 344. doi: 10.1016/ S0008-6223(99)00109-8.

14. Raymundo-Pinero, E., Cazorla-Amorós, D. \& LinaresSolano, A. (2001). Temperature programmed desorption study on the mechanism of $\mathrm{SO}_{2}$ oxidation by activated carbon and activated carbon fibres. Carbon 39, 231 - 242. doi:10.1016/S0008-6223(00)00119-6.

15. Khavrus, V.O., Lemesh, N.V., Gordijchuk, S.V., Tripolsky, A.I., Iwashchenko, T.S., Biliy, M.M. \& Strizhak, P.E. (2008). Chemical catalytic vapor deposition (CCVD) synthesis of carbon annotubes by decomposition of ethylene on metal (Ni, $\mathrm{Co}, \mathrm{Fe})$ nanoparticles. React. Kinet. Catal. Lett. 93, 295 - 303. doi: 10.1007/s11144-008-5225-6.

16. Donato, M.G., Messina, G., Milone, C., Pristone, A. \& Santangelo, S. (2008). Experiments on C nanotubes synthesis by Fe-assisted ethane decomposition. Diam. Relat. Mater. 17, 318 - 324. doi: 10.1016/j.diamond.2007.12.043.

17. Nagaraju, N., Fonseca, A., Konya, Z. \& Nagy, J.B. (2002). Alumina and silica supported metal catalysts for the production of carbon nanotubes. J. Mol. Catal. A-Chem. 181, 57 - 62. doi: S1381-1169(01)00375-2.

18. Escobar, M., Moreno, M.S., Candal, R.J. Marchi, M.C., Caso, A., Polosecki, P.I. Rubiolo, G.H. \& Goyanes S. (2007). Synthesis of carbon nanotubes by CVD: Effect of acetylene pressure on nanotubes characteristics. Appl. Surf. Sci. 254, 251 - 256. doi: 10.1016/j.apsusc.2007.07.044.
19. Tripol'skii, A.I., Lemesh, N.V., Khavrus', V.A. \& Strizhak, P.E. (2008). Morphology of carbon nanotubes, obtained by decomposition of ethylene on nickel nanoparticles at various rates of flow and concentration of $\mathrm{C}_{2} \mathrm{H}_{2}$. Theor. Exp. Chem. 44, 240 - 244. doi: 0040-5760/08/ 4404-0240.

20. Venegoni, D., Serp, P., Feurer, R., Kihn, Y., Vahlas, C. \& Kalck, P. (2002). Parametric study for the growth of carbon nanotubes by catalytic chemical vapor deposition in a fluidized bed reactor. Carbon 40, 1799 - 1807. doi: S00086223(02)00057-X.

21. Ermakova, M.A., Ermakov, D.Y, Chuvilin, A.L. \& Kushinov, G.G. (2001). Decomposition of methane over iron catalyst at the range of moderate temperatures: the influence of structure of the catalytic systems and the reaction conditions on the yield of carbon and morphology of carbon filaments. J. Catal. 201, 183 - 197. doi:10.1006/ jcat.2001.3243. 